\title{
The need for a coordinated action to elucidate ecological occurrence and functions of endophytic fungal communities
}

\author{
Rosario Nicoletti ${ }^{1,2, *}$, Francesco Vinale ${ }^{3,4}$ \\ ${ }^{1}$ Council for Agricultural Research and Economics, Research Centre for Olive, Fruit and Citrus Crops, 81100 Caserta, Italy \\ ${ }^{2}$ Department of Agricultural Sciences, University of Naples Federico II, 80055 Portici, Italy \\ ${ }^{3}$ Department of Veterinary Medicine and Animal Productions, University of Naples Federico II, 80137 Naples, Italy \\ ${ }^{4}$ Institute for Sustainable Plant Protection, National Research Council, 80055 Portici, Italy
}

\begin{abstract}
Research concerning endophytic fungi has recently received a remarkable boost following a general trend to investigate and exploit biodiversity in all its forms, and because of the easier access to equipment and methods, which enables quicker identification procedures. The available data highlight that, besides the plant hosts, endophytes consistently interact with the other components of biocoenosis, and that the assortment of the microbial consortium is also to be considered on account of the reciprocal influence between the several species which are part of it. Unravelling these complex ecological relationships is fundamental because of possible translational applications, particularly regarding crop management. However, this requires that the available information concerning plant species, ecological contexts or functional categories of endophytes is examined fully. In this aim, a coordinated effort appears to be necessary to organise the current knowledge to increase the significance and the practical impact of new findings.
\end{abstract}

Keywords: crop protection, defensive mutualism, endophytes, plant fitness, plant microbiome

\section{INTRODUCTION}

Although etymology of the word refers to a general aptitude to dwell inside plants, the concept of endophytic fungi in plant ecology has been recently adopted in a stricter sense. Several definitions have been enunciated by authoritative scientists in the field which are all based on the condition of not causing any immediate overt negative effect to the host (Arnold, 2007; Saikkonen, 2007; Hyde and Soytong, 2008; Jia et al., 2016; Yan et al., 2019). Despite the first pioneering observations that dates back to the nineteenth century (de Bary, 1866), a consolidated prejudice that pathogens basically were the only microorganisms that can invade and colonise living plant tissues has delayed the awareness that endophytic fungi are constantly associated with plants, and remarkably influence their ecological fitness. Through the past few decades, the curiosity of a slowly increasing number of investigators scattered around the world has resulted in the spread of the general theoretical intent that all components of biodiversity have to be exploited for the benefit of humanity, with ensuing results in terms of literature proliferation (Staniek et al., 2008; Nicoletti and Fiorentino, 2015; Uzma et al., 2018; Gupta et al., 2020).

Nowadays, it can be said that the community of scientists involved in studies concerning endophytic fungi is at the middle of the ford the awareness of the relevance of the subject of their studies, as well as the access to the basic laboratory techniques/equipment, are widespread; still, there is a gap to be covered for attaining to a thorough understanding of this fascinating biological phenomenon, and achieving a significant impact in crop science. 


\section{ENDOPHYTES, PATHOGENS, OR BOTH}

Results of recent investigations show that the border between pathogenicity and endophytism is inconspicuous, and the conversion of a pathogen into an endophyte may be due to the occasional incidence of any environmental factor, or even mutation of a single gene controlling disease development. Moreover, many cases have been described of plant pathogens, which start colonisation of plant tissues behaving like true endophytes, and only turn into causing detrimental effects to their hosts after such a delicate balance is disrupted by some external condition. This behaviour particularly characterises some taxonomic groupings such as the Botryosphaeriaceae (Slippers and Wingfield, 2007; Salvatore et al., 2020). More consistent and generally accepted is the inference that the ecological success of endophytic fungi basically relies on their saprophytic aptitude, which allows them to thrive on the organic matter available when plant tissues start senescence. From a more conceptual point of view, the endophytic condition has been proposed to represent an adaptation of pathogenicity involving reduction of virulence and extension of the latency period (Saikkonen, 2007). Whatever the real direction driving the evolution, the result is that there are plenty of fungal species that are considered either pathogens or endophytes depending on the investigational contexts. Any attempt to provide an exhaustive overview of such species would turn into vain since an extremely long list would result requiring to be continuously updated and integrated upon evidence of conversions in either sense.

\section{OCCURRENCE}

Without considering mycorrhizae, another eco-functional category which historically has been treated independently from the rest of plant-associated fungi (Abdel-Latef et al., 2016), the first systematic investigations concerning endophytic fungi probably date back to the case of Epichloë/Neotyphodium species associated with ryegrasses (Lolium spp.), as incited by the necessity to elucidate the causes of livestock poisoning (McClennan, 1920; Sampson, 1935). Afterwards resulting in more fodder and non-fodder plants, the particular mutualistic relationship established between these fungi and their hosts is based on the capacity to spread systemically within the plant tissues, permeating them with compounds which are toxic to herbivorous organisms, and colonise seeds to ensure vertical transmission. This common aptitude has induced to treat these endophytes as a homogeneous category, the so-called clavicipitaceous fungi, for which several fine reviews resuming the state of the art are available (Kuldau and Bacon, 2008; Di Menna et al., 2012; Panaccione et al., 2014; Simpson et al., 2014).

The residual category of the non-clavicipitaceous fungi is much more numerous and much less homogeneous (Rodriguez et al., 2009; Sanchez Márquez et al., 2012; Nicoletti and Fiorentino, 2015). They are considered to inhabit practically every plant species, regardless of the environmental conditions. Studies carried out on the only two vascular plant species known to have colonised Antarctica demonstrated the occurrence of both known and new fungal species developing endophytically (Rosa et al., 2009, 2010; Upson et al., 2009a; Kessler de Andrade et al., 2018). On the opposite environmental side, their occurrence has also been documented in the few plant species that can survive in the hyperarid desert of Atacama (Conley et al., 2006; González-Teuber et al., 2017).

In phytogeographic terms, there are indications that endophytic fungi communities change regarding several factors. Even regarding taxonomic aggregates, it has been observed that the Helotiales dominate in forests, while the Pleosporales more often characterise the species assemblage in grasslands (Jumpponen et al., 2017). Single species may display specific adaptation, particularly when they tend to colonise the whole plant and are vertically transmitted, such as those reported in forbs (Hodgson et al., 2014). Other cases of specific associations may concern discrete plant tissues/organs. In this respect, a meaningful example is represented by Penicillago nodositata, which was first described as Penicillium nodositatum in strict relationship with alder (Alnus spp.) where it typically forms as myconodules on roots (Valla et al., 1989). However, additional findings of this species in herbivore dung (Guevara-Suarez et al., 2020) suggest some caution in building arbitrary inferences from limited data.

It can be said that for endophytic fungi specialisation represents anything but a rule. In fact, a tendency to spread throughout the ecological context and to colonise taxonomically unrelated hosts has been documented in several cases, such as for species of Mycosphaerella/ Septoria, dominating the endophytic assemblage in riparian areas in Arizona (Lau et al., 2013), and Diaporthe foeniculina, widespread in an Italian forest site (Carrieri et al., 2014). Besides Diaporthe/Phomopsis, species of genera such as Colletotrichum, Pestalotiopsis, Guignardia/Phyllosticta and Xylaria have also been reported for such a pervasive aptitude (Suryanarayanan et al., 2018; Nicoletti, 2019; Nicoletti et al., 2020). As discussed in the above-mentioned paper (Saikkonen, 2007), for horizontally transmitted endophytes all factors increasing spore production and dispersion are direct determinants of their spread and relative occurrence. Particularly, the animal component of the ecosystems in its multifaceted aspects may represent a fundamental vehicle (Devarajan and Suryanaranayan, 2006). And even genetic factors have a role in possibly affecting the interactions with endophytic fungi, especially when promiscuity of closely related plant species is conducive for hybridisation and introgression. Considerations on the genetic interactions with plants also induce to expect that species assemblages and/or the degree of host specialisation of endophytes be correlated to the botanical diversity in a certain environmental context 
(Saikkonen, 2007). In another instance, the ability to establish relationships with various endophytic fungi has been considered as a basic factor helping invasive plants to respond to abiotic stresses in the colonization of new environments (Soares et al., 2016).

\section{DEFENSIVE MUTUALISM}

The above-mentioned aptitude by clavicipitaceous endophytic fungi is introductory to the consolidated concept of defensive mutualism, that is the improvement of plant fitness resulting after the acceptance of a symbiont releasing toxic metabolites or stimulating metabolic adaptations which ensure some extent of protection against pests (Luo et al., 2015). Rather than being limited to species in the Clavicipitaceae, a similar relationship has been recently demonstrated involving species of the genus Undifilum (Pleosporaceae) endophytic in plants from a few genera in the Fabaceae, producing the alkaloid swainsonine, which results in being toxic to cattles (Grum et al., 2013; Nicoletti and Fiorentino, 2015). Undoubtedly, it is meaningful that analogous successful symbiotic relationships involve plant and fungal species, which are distantly related in taxonomic terms. More directly, it is a clear indication that this model is widespread, and that it may represent a natural outcome of the evolutionary forces operating in ecosystems. In fact, apart from those disclosed after the implications on livestock, there are more known cases where endophytic fungi protect plants from aggression by other kinds of herbivorous organisms, particularly insects (Hartley and Gange, 2009; Miller et al., 2009; Eberl et al., 2019). The same concept applies to plant pathogens, with the obvious difference that the alleged bioactive products express their activity in terms of antibiosis rather than after ingestion (Busby et al., 2016; Brader et al., 2017). On a further instance, endophytic fungi may contribute to reducing disease severity caused by fungal pathogens by upregulating many defence-related genes of the host (Mejía et al., 2014; Waqas et al., 2015).

An emblematic protagonist of the multifaceted interactions connecting plants, endophytic fungi and pests is the cosmopolitan species Botryosphaeria dothidea. In fact, although primarily known as a pathogen of some forest trees, this fungus has a dramatically large host range resulting after its widespread occurrence as an endophyte (Marsberg et al., 2017). But even more striking is its implication in the tripartite relationship established with midges belonging to the Asphondyliinae (Diptera, Cecidomyidae) inducing the formation of galls on flowers and other organs of a multitude of plant species; possibly inoculated at oviposition, the fungus develops a mycelial mat lining the gall walls which represents the feeding substrate for the larvae (Zimowska et al., 2020b).

It has been documented that even nutritional aspects may sometimes be entailed in defensive mutualism; for instance, in plants that absorb nitrogen released in their tissues from insects killed after infection by endophytic entomopathogenic fungi (Behie et al., 2012). More often the nutritional implications of endophyte colonisation are direct; in fact, in many cases they have been reported to help the host plants to better assimilate nitrogen, phosphorus, sulfur, magnesium, iron, calcium and potassium (Usuki and Narisawa, 2007; Upson et al., 2009b; Yadav et al., 2010) or simply degrade complex compounds to simpler molecules that are more readily available for root absorption (Porras-Alfaro and Bayman, 2011).

Finally, endophytic fungi have been reported to improve plant fitness also regarding other abiotic stresses, such as drought, salinity, extreme temperatures and heavy metal toxicity. Again, the many cases known in this respect are more exhaustively treated in several dedicated reviews (Khan et al., 2015; Jia et al., 2016; Lugtenberg et al., 2016; Deng and Cao, 2017; Yan et al., 2019).

\section{SECONDARY METABOLITES}

As introduced above, defensive mutualism can be mediated by the production of secondary metabolites which disclose toxic or antibiotic effects towards pests. As research in the field progresses, the list of these compounds lengthens at an extraordinarily high rate. Besides adding previously unknown metabolites with interesting properties, research in the field makes it more and more evident that many bioactive products originally extracted from plants are commonly produced by some of their associated endophytes. Such an ability is often shared by several taxonomically unrelated strains (Nicoletti et al., 2018), which in turn can establish synergistic interactions resulting in enhanced production (Bhumika et al., 2016). Indeed, this is quite a hot research subject for medicinal plants in particular, as outlined in several recent reviews (Ludwig-Müller, 2015; Jia et al., 2016; Caruso et al., 2020; Zimowska et al., 2020a).

Besides biotechnological implications deriving from the possibility to use microbial strains in industrial processes for the production of plant-derived drugs (Venugopalan and Srivastava, 2015), such a high number of cases involving phylogenetically unrelated fungi and their host plants is indicative that the symbionts may share a common genetic base for the biosynthesis of these compounds, and that they are eventually able to perform horizontal gene transfer at some extent. Several convergent clues have been gathered in this respect also involving direct cross-talks between endophytes (Fitzpatrick, 2012; Barelli et al., 2016; Manganiello et al., 2019). In this process of transfer of genetic information, a fundamental role is conjectured to be played by other microorganisms, particularly bacteria (Schmitt and Lumbsch, 2009). In fact, fungi can in turn be hosts of 'endohyphal' bacteria which represent a possible vehicle for a natural genomic transformation, or the real actors of the biosynthetic process. An example is represented by the production of rhizoxin by Paraburkholderia rhizoxinica, a new species discovered in hyphae of Rhizopus microsporus from which this antimitotic 
macrolide was originally characterised (PartidaMartinez and Hertweck, 2007). Considering that endohyphal bacteria are of widespread occurrence in endophytic fungi (Hoffman and Arnold, 2010; Shaffer et al., 2016), more cases can be expected to result where these eco-physiological interactions are crucial in shaping the biosynthetic aptitudes of the symbionts.

The ability by endophytic fungi to directly produce bioactive metabolites of their host plants also conceptually implies a take-over of the biomolecular mechanisms enabling avoidance of self-toxic effects (Naik et al., 2019), representing a fundamental requisite for their survival in an environment that is permeated with these toxic substances. In this respect, it is not at all surprising that endophytes, by their own condition of inhabitants of plant tissues, have acquired this capacity, and that the subtended evolutionary adaptations may be shared by series of endophytic strains in most plant species.

\section{CONCLUSIONS}

In view of boosting a translational follow-up, future research on endophytic fungi should be better focused on the elucidation of the mechanisms of interactions established with the host plants and their pests and pathogens, and the ensuing ecological and evolutionary consequences. Particularly, the introduction of selected species/strains into plants to enhance crop performance might be somehow hampered in the absence of adequate knowledge concerning the interactions and the spacetime associations of the pool of microorganisms forming such peculiar biocoenoses. Indeed, the available data are quite fragmentary and, as they increase in amount, there seems to be no perspective that they are systematically analysed because of a possible extrapolation of any relevant aspects which may improve our knowledge in this respect.

The pioneering instinct which has guided forerunner investigators in elucidating some of the aspects concisely examined in this article is no more adequate. Our feeling is that in the current historical moment a global effort is desirable to integrate the outcome of the manifold independent observations disclosed so far to address future research towards more fruitful biotechnological applications, particularly in the aim to improve crop yields.

\section{FUNDING}

This research was funded by the following projects: POR FESR Campania 2014/2020-O.S. 1.1 (Grant number Bioagro 559); MISE CRESO (Grant number Protection n. F/050421/01-03/X32); PSR Veneto 16.1.1 (Grant number Divine n. 3589659); PSR Campania 2014/2020 Misura 16 - Tipologia di intervento 16.1 Azione 2 Sostegno ai Progetti Operativi di Innovazione Progetto DI.O.N.IS.O., C.U.P. B98H19005010009; PRIN
2017 (Grant number PROSPECT 2017JLN833); MISE Sportello Agrifood DM 5/3/2018 (Grant VIABio).

\section{AUTHOR CONTRIBUTIONS}

R.N. - conceptualisation. R.N. and F.V - resources. R.N. and F.V. - writing, original draft preparation, review and editing. All authors have read and agreed to the published version of the manuscript.

\section{CONFLICTS OF INTEREST}

Authors declare no conflict of interest.

\section{REFERENCES}

Abdel-Latef, A. A. H., Hashem, A., Rasool, S., Abd_Allah, E. F., Alqarawi, A. A., Egamberdieva, D., JAN, S., ANJum, N. A., AND Ahmad, P. (2016). Arbuscular mycorrhizal symbiosis and abiotic stress in plants: A review. Journal of Plant Biology, 59, 407-426.

Arnold, A. E. (2007). Understanding the diversity of foliar endophytic fungi: Progress, challenges, and frontiers. Fungal Biology Reviews, 21, 51-66.

Barelli, L., Moonjely, S., Behie, S. W., And Bidochka, M. J. (2016). Fungi with multifunctional lifestyles: Endophytic insect pathogenic fungi. Plant Molecular Biology, 90, 657-664.

Behie, S. W., Zelisko, P. M., and Bidochka, M. J. (2012). Endophytic insect-parasitic fungi translocate nitrogen directly from insects to plants. Science, 336, 1576-1577.

Bhumika, N. B., Swapnil, M. P., And Sanjay, P. G. (2016). Camptothecine production by mixed fermentation of two endophytic fungi from Nothapodytes nimmoniana. Fungal Biology, 120, 819-894.

Brader, G., Compant, S., Vescio, K., Mitter, B., Trognitz, F., MA, L. J., And Sessitsch, A. (2017). Ecology and genomic insights into plant-pathogenic and plant-nonpathogenic endophytes. Annual Review of Phytopathology, 55, 61-83.

Busby, P. E., Ridout, M., And Newcombe, G. (2016). Fungal endophytes: Modifiers of plant disease. Plant Molecular Biology, 90, 645-655.

Carrieri, R., Lahoz, E., And Nicoletti, R. (2014). Widespread endophytic occurrence of Phomopsis theicola (teleomorph Diaporthe foeniculina) at the Astroni Nature Reserve. Journal of Plant Pathology, 96, S4.46.

Caruso, G., Abdelhamid, M. T., Kalisz, A., And SEKARA, A. (2020). Linking endophytic fungi to medicinal plants therapeutic activity. A case study on Asteraceae. Agriculture, 10, 286, doi: 10.3390/ agriculture 10070286.

Conley, C. A., Ishrhanova, G., Mckay, C. P., And Cullungs, K. (2006). A preliminary survey of nonlichenized fungi cultured from the hyperarid Atacama Desert of Chile. Astrobiology, 6,521-526. 
DE BARY, A. (1866). Morphologie und Physiologie der Pilze, Flechten und Myxomyceten. Leipzig, Germany: Engelmann.

Deng, Z., And CaO, L. (2017). Fungal endophytes and their interactions with plants in phytoremediation: A review. Chemosphere, 168, 1100-1106.

Devarajan, P. T., and Suryanarayanan, T. S. (2006). Evidence for the role of phytophagous insects in dispersal of non-grass fungal endophytes. Fungal Diversity, 23, 111-119.

Di Menna, M. E., Finch, S. C., Popay, A. J., And Smith, B. L. (2012). A review of the Neotyphodium lolii/ Lolium perenne symbiosis and its associated effects on animal and plant health, with particular emphasis on ryegrass staggers. New Zealand Veterinary Journal, 60, 315-328.

Eberl, F., Uhe, C., And Unsicker, S. B. (2019). Friend or foe? The role of leaf-inhabiting fungal pathogens and endophytes in tree-insect interactions. Fungal Ecology, 38, 104-112.

FitzPATRicK, D. A. (2012). Horizontal gene transfer in fungi. FEMS Microbiology Letters, 329, 1-8.

GonzÁlez-Teuber, M., Vilo, C., And BascuñÁn-Godoy, L. (2017). Molecular characterization of endophytic fungi associated with the roots of Chenopodium quinoa inhabiting the Atacama Desert, Chile. Genomics Data, 11, 109-112.

Grum, D. S., Cook, D., Baucom, D., Моtт, I. W., Gardner, D. R., Creamer, R., and Allen, J. G. (2013). Production of the alkaloid swainsonine by a fungal endophyte in the host Swainsona canescens. Journal of Natural Products, 76, 1984-1988.

Guevara-suarez, M., García, D., Cano-Lira, J. F., Guarro, J., AND Gené, J. (2020). Species diversity in Penicillium and Talaromyces from herbivore dung, and the proposal of two new genera of penicilliumlike fungi in Aspergillaceae. Fungal Systematics and Evolution, 5, 39-75.

Gupta, S., Chaturvedi, P., Kulkarni, M. G., and Van Staden, J. (2020). A critical review on exploiting the pharmaceutical potential of plant endophytic fungi. Biotechnology Advances, 39, 107462, doi: 10.1016/j. biotechadv.2019.107462

Hartley, S. E., And Gange, A. C. (2009). Impacts of plant symbiotic fungi on insect herbivores: mutualism in a multitrophic context. Annual Review of Entomology, 54, 323-342.

Hodgson, S., De cates, C., Hodgson, J., Morley, N. J., Sutton, B. C., And Gange, A. C. (2014). Vertical transmission of fungal endophytes is widespread in forbs. Ecology and Evolution, 4, 1199-1208.

Hoffman, M. T., And Arnold, A. E. (2010). Diverse bacteria inhabit living hyphae of phylogenetically diverse fungal endophytes. Applied and Environmental Microbiology, 76, 4063-4075.

Hyde, K. D., and Soytong, K. (2008). The fungal endophyte dilemma. Fungal Diversity, 33, 163-173.

JiA, M., Chen, L., Xin, H. L., Zheng, C. J., Rahman, K., HAN, T., AND QIN, L. P. (2016). A friendly relationship between endophytic fungi and medicinal plants: A systematic review. Frontiers in Microbiology, 7, 906, doi: 10.3389/fmicb.2016.00906.

Jumpronen, A., Herrera, J., Porras-alfaro, A., And Rudgers, J. (2017). Biogeography of root-associated fungal endophytes. In L. Tedersoo (Ed.), Biogeography of mycorrhizal symbiosis (pp. 195-222). Cham, Switzerland: Springer.

Kessler, D. E., Andrade, G. A., Peña Cañón, E. R., Paidano Alves, R., Schmitz, D., Schünemann, A. L., Pereira De Albuquerque, M., Putzke, J., Pereira, A. B., and De Carvalho Victoria, F. (2018). First record of Juncaceicola as endophytic fungi associated with Deschampsia antarctica Desv. Diversity, 10(4), 107, doi: 10.3390/d10040107.

Khan, A. L., Hussain, J., Al-Harrasi, A., Al-Rawahi, A., AND LeE, I. J. (2015). Endophytic fungi: resource for gibberellins and crop abiotic stress resistance. Critical Reviews in Biotechnology, 35, 62-74.

Kuldau, G., AND Bacon, C. (2008). Clavicipitaceous endophytes: Their ability to enhance resistance of grasses to multiple stresses. Biological Control, 46, 57-71.

Lau, M. K., Arnold, A. E., And Johnson, N. C. (2013). Factors influencing communities of foliar fungal endophytes in riparian woody plants. Fungal Ecology, 6, 365-378.

Ludwig-Müller, J. (2015). Plants and endophytes: equal partners in secondary metabolite production? Biotechnology Letters, 37, 1325-1334.

Lugtenberg, B. J., Caradus, J. R., and Johnson, L. J. (2016). Fungal endophytes for sustainable crop production. FEMS Microbiology Ecology, 92(12), fiw 194, doi: 10.1093/femsec/fiw 194.

Luo, H., XIE, L., Zeng, J., AND XIE, J. (2015). Biosynthesis and regulation of bioprotective alkaloids in the gramineae endophytic fungi with implications for herbivores deterrents. Current Microbiology, 71, 719-724.

Manganiello, G., Marra, R., Staropoli, A., Lombardi, N., Vinale, F., And Nicoletti, R. (2019). The shifting mycotoxin profiles of endophytic Fusarium strains: A case study. Agriculture, 9, 143, doi: 10.3390/ agriculture9070143.

Marsberg, A., Kemler, M., Jami, F., Nagel, J. H., PostmaSmidt, A., Naidoo, S., Wingfield, M. J., Crous, P. W., Spatafora, J. W., Hesse, C. N., Robbertse, B., AND SLIPPERS, B. (2017). Botryosphaeria dothidea: A latent pathogen of global importance to woody plant health. Molecular Plant Pathology, 18, 477-488.

McclennAn, E. (1920). The endophytic fungus of Lolium. Part I. Proceedings of the Royal Society, Victoria (NSW), 11, 252-301.

Mejía, L. C., Herre, E. A., Sparks, J. P., Winter, K., García, M. N., van Bael, S.A., Stitt, J., Shi, Z., Zhang, Y., Guiltinan, M. J., and Maximova, S. N. (2014). Pervasive effects of a dominant foliar endophytic fungus on host genetic phenotypic expression in 
a tropical tree. Frontiers in Microbiology, 5, 479, doi: 10.3389/fmicb.2014.00479.

Miller, J. D., Cherid, H., Sumarah, M. W., and Adams, G. W. (2009). Horizontal transmission of the Picea glauca foliar endophyte Phialocephala scopiformis CBS 120377. Fungal Ecology, 2, 98-101.

Naik, S., ShaAnker, R. U., Ravikanth, G., ANd Dayanandan, S. (2019). How and why do endophytes produce plant secondary metabolites? Symbiosis, 78, 193-201.

Nicoletti, R. (2019). Endophytic fungi of citrus plants. Agriculture, 9, 247, doi: 10.3390/agriculture9120247.

Nicoletti, R., Di Vaio, C., and Cirillo, C. (2020). Endophytic fungi of olive tree. Microorganisms, 8(9), 1321, doi: 10.3390/microorganisms8091321.

Nicoletti, R., Fiorentino, A. (2015). Plant bioactive metabolites and drugs produced by endophytic fungi of Spermatophyta. Agriculture, 5, 918-970.

Nicoletti, R., Salvatore, M. M., Ferranti, P., and Andolfi, A. (2018). Structures and bioactive properties of myrtucommulones and related acylphloroglucinols from Myrtaceae. Molecules, 23, 3370, doi: 10.3390/molecules23123370.

Panaccione, D. G., Beaulieu, W. T., and Cook, D. (2014). Bioactive alkaloids in vertically transmitted fungal endophytes. Functional Ecology, 28, 299-314.

Partida-Martinez, L. P., and Hertweck, C. (2007). A gene cluster encoding rhizoxin biosynthesis in "Burkholderia rhizoxina", the bacterial endosymbiont of the fungus Rhizopus microsporus. ChemBioChem, $8,41-45$.

Porras-Alfaro, A., And Bayman, P. (2011). Hidden fungi, emergent properties: Endophytes and microbiomes. Annual Review of Phytopathology, 49, 291-315.

Rodriguez, R. J., White JR, J. F., Arnold, A. E., And Redman, A. R. A. (2009). Fungal endophytes: Diversity and functional roles. New Phytologist, 182, 314-330.

Rosa, L. H., Almeida vieira, M. D. L., Santiago, I. F., Rosa, C. A. (2010). Endophytic fungi community associated with the dicotyledonous plant Colobanthus quitensis (Kunth) Bartl. (Caryophyllaceae) in Antarctica. FEMS Microbiology Ecology, 73, 178-189.

Rosa, L. H., VAZ, A. B., Caligiorne, R. B., Campolina, S., AND Rosa, C. A. (2009). Endophytic fungi associated with the Antarctic grass Deschampsia antarctica Desv. (Poaceae). Polar Biology 32, 161-167.

SAIKKONEN, K. (2007). Forest structure and fungal endophytes. Fungal Biology Reviews, 21, 67-74.

Salvatore, M. M., Andolfi, A., And Nicoletti, R. (2020). The thin line between pathogenicity and endophytism: The case of Lasiodiplodia theobromae. Agriculture, 10(10), 488, doi: 10.3390/agriculture 10100488 .

Sampson, K. (1935). The presence and absence of an endophytic fungus in Lolium temulentum and L. perenne. Transactions of the British Mycological Society, 19, 337-343.

Sanchez Márquez, S., Bills, G. F., Herrero, N., and ZabalgogeazcoA, I. (2012). Non-systemic fungal endophytes of grasses. Fungal Ecology, 5, 289-297.
SchmitT, I., AND Lumbsch, H. T. (2009). Ancient horizontal gene transfer from bacteria enhances biosynthetic capabilities of fungi. PLOS ONE, 4(2), e4437, doi: 10.1371/journal.pone.0004437.

Shaffer, J. P., Sarmiento, C., Zalamea, P. C., Gallery, R. E., Davis, A. S., Baltrus, D. A., and Arnold, A. E. (2016). Diversity, specificity, and phylogenetic relationships of endohyphal bacteria in fungi that inhabit tropical seeds and leaves. Frontiers in Ecology and Evolution, 4, 116, doi: 10.3389/fevo.2016.00116.

Simpson, W. R., Faville, M. J., Moraga, R. A., Williams, W. M., Mcmanus, M. T., and Johnson, R. D. (2014). Epichloë fungal endophytes and the formation of synthetic symbioses in Hordeeae (= Triticeae) grasses. Journal of Systematics and Evolution, 52, 794-806.

Slippers, B., AND Wingfield, M. J. (2007). Botryosphaeriaceae as endophytes and latent pathogens of woody plants: Diversity, ecology and impact. Fungal Biology Reviews, 21, 90-106.

Soares, M. A., Li, H. Y., Kowalski, K. P., Bergen, M., Torres, M. S., AND White, J. F. (2016). Evaluation of the functional roles of fungal endophytes of Phragmites australis from high saline and low saline habitats. Biological Invasions, 18, 2689-2702.

Staniek, A., Woerdenbag, H. J., and Kayser, O. (2008). Endophytes: Exploiting biodiversity for the improvement of natural product-based drug discovery. Journal of Plant Interactions, 3, 75-93.

Suryanarayanan, T. S., Devarajan, P. T., Girivasan, K. P., Govindarajulu, M. B., Kumaresan, V., Murali, T. S., Rajamani, T., Thirunavukkarasu, N., and Venkatesan, G. (2018). The host range of multi-host endophytic fungi. Current Science, 115, 1963-1969.

Upson, R., Newsham, K. K., Bridge, P. D., Pearce, D. A., AND ReAD, D. J. (2009a). Taxonomic affinities of dark septate root endophytes of Colobanthus quitensis and Deschampsia antarctica, the two native Antarctic vascular plant species. Fungal Ecology, 2, 184-196.

Upson, R., Read, D. J., and Newsham, K. K. (2009b). Nitrogen form influences the response of Deschampsia antarctica to dark septate root endophytes. Mycorrhiza, 20, 1-11.

Usuki, F., and Narisawa, K. (2007). A mutualistic symbiosis between a dark septate endophytic fungus, Heteroconium chaetospira, and a nonmycorrhizal plant, Chinese cabbage. Mycologia, 99, 175-184.

Uzma, F., Mohan, C. D., Hashem, A., Konappa, N. M., Rangappa, S., Kamath, P. V., Singh, B. P., Mudili, V., Gupta, V. K., Siddaiah, C. N., Chowdappa, S., Alqarawi, A. A., and AbD_Allah, E. F. (2018). Endophytic fungi-alternative sources of cytotoxic compounds: A review. Frontiers in Pharmacology, 9, 309, doi: 10.3389/fphar.2018.00309.

Valla, G., Capellano, A., Hugueney, R., and Moiroud, A. (1989). Penicillium nodositatum Valla, a new species inducing myconodules on Alnus roots. Plant and Soil, 114, 142-146. 
Venugopalan, A., And SRivastava, S. (2015). Endophytes as in vitro production platforms of high value plant secondary metabolites. Biotechnology Advances, 33, 873-887.

Waqas, M., Khan, A. L., Muhammad, H., Shahzad, R., Kang, S. M., Kim, J. G., And Lee, I. J. (2015). Endophytic fungi promote plant growth and mitigate the adverse effects of stem rot: An example of Penicillium citrinum and Aspergillus terreus. Journal of Plant Interactions, 10, 280-287.

Yadav, V., Kumar, M., Deep, D. K., Kumar, H., Sharma, R., Tripathi, T., Tuteja, N., Saxena, A. K., And Johri, A. K. (2010). A phosphate transporter from the root endophytic fungus Piriformospora indica plays a role in phosphate transport to the host plant. Journal of Biological Chemistry, 285, 26532-26544.
Yan, L., Zhu, J., ZhaO, X., Shi, J., JiAng, C., AND ShaO, D. (2019). Beneficial effects of endophytic fungi colonization on plants. Applied Microbiology and Biotechnology, 103, 3327-3340.

Zimowska, B., Bielecka, M., AbramczyK, B., AND Nicoletti, R. (2020a). Bioactive products from endophytic fungi of sages (Salvia spp.). Agriculture, 10(11), 543, doi: 10.3390/agriculture10110543.

Zimowska, B., Okoń, S., Becchimanzi, A., Krol, E. D., AND Nicoletti, R. (2020b). Phylogenetic characterization of Botryosphaeria strains associated with Asphondylia galls on species of Lamiaceae. Diversity, 12(2), 41, doi: 10.3390/d12020041.

Received: December 16, 2020; accepted: January 15, 2021. 